\title{
Neuronal nicotinic alpha7 receptors modulate early neutrophil infiltration to sites of skin inflammation
}

\author{
Lorise C Gahring*1,2,3, Amber V Osborne 1,2,3, Michelle Reed ${ }^{1,2}$ and Scott W Rogers 1,4
}

\begin{abstract}
Background: A major site of initiation of inflammatory responses upon physical perturbation(s) and infection by invading organisms is the skin. Control of responses in this organ is, in part, modulated by the neuronal nicotinic acetylcholine receptor (nAChR) alpha7.

Methods: To further investigate the role of alpha7 in skin inflammatory responses, a local inflammatory response was induced by topical application of croton oil to the ear skin of wild-type (alpha7WT) and alpha7 knock-out (alpha7KO) mice. Cells infiltrating the inflamed tissue were characterized by flow cytometry and RNA analysis.

Results: Six hours following croton oil application, analysis of infiltrating cells showed that the alpha7KO mice exhibited a significantly enhanced number of cells, and specifically, of Ly6G positive neutrophils. Macrophage and lymphocyte infiltration was equivalent in the alpha7KO and alpha7WT mice. RNA analysis showed that IL-1 $\beta$ and IL-6 were increased significantly in the infiltrating cells of the alpha7KO mouse, although TNF failed to reach significance. In contrast, resident cells of the skin exhibited no differences in these cytokines between genotypes. Both resident and infiltrating cell populations from alpha7KO mice did show elevated message levels for the adhesion protein ICAM1. Measurement of chemokines revealed enhanced expression of the skin-related CCL27 by resident cells in alpha7KO mice. Further, we demonstrate that the population of $\mathrm{Ly}_{6 \mathrm{G}}+$ neutrophils at the croton oil-inflamed skin site expresses low levels of CCR10, a receptor for CCL27 normally associated with lymphocytes.

Conclusion: nAChRalpha7 in the skin can impact on early local inflammatory responses mediated through a novel population of neutrophils that are Ly6G ${ }^{+} \mathrm{CCR} 10^{\mathrm{l}}$.
\end{abstract}

\section{Background}

Neuronal nicotinic acetylcholine receptors (nAChR) are well characterized for their role(s) in modulating neurotransmission including the addictive response to nicotine $[1,2]$. However, these ligand-activated ionotropic receptors, particularly the distinct subtype termed alpha7 $(\alpha 7)$, also participate in non-neuronal peripheral systems to impact upon pro-inflammatory responses [3-6]. Not unlike $\alpha 7$ in the nervous system, the effects of $\alpha 7$ activity peripherally can vary greatly depending upon where it is expressed and in which cell type. In neurons, the $\alpha 7$ receptor antagonizes TNF $\alpha$-induced neuroprotection in primary cultures; and in peripheral organs receiving vagal

* Correspondence: Lorise.Gahring@hsc.utah.edu

${ }^{1}$ Geriatric Research, Education and Clinical Center, Salt Lake City VA Medical Center, USA

Full list of author information is available at the end of the article innervation, the $\alpha 7$ receptor impacts upon inflammatory responses [4,7]. A robust contribution by $\alpha 7$ towards modulating inflammatory cytokine production in the skin is also present and occurs independently of vagalparasympathetic innervation (e.g. see discussion in $[3,8]$ ). Keratinocytes appear to be the primary source of acetylcholine $(\mathrm{ACh})$ in the skin [4] but further investigation regarding other cell sources is needed.

The skin is a first line of defense against many pathogenic agents and is exposed to many external agents that are pro-inflammatory (e.g., UVB or sunburn and topical irritants) as well as to agents that modify $\alpha 7$ function such as nicotine. Almost 30 years ago it was recognized that nicotine could alter wound healing in rabbit ears [9]. Since then, it has been further demonstrated that keratinocytes express nicotinic receptors and modulation in 
wound healing can be mediated, in part, through nicotinic receptors $\alpha 3, \alpha 4, \alpha 5$ and $\alpha 7$ [10-13]. Keratinocyte expression of $\alpha 7$ has been demonstrated using in situ hybridization, double-labeling immunofluorescence, and patch-clamp studies $[14,15]$, and respond to nicotine. In tissue culture systems, Grando et al. [16] have demonstrated that nicotine increases cell-cell adherence of cultured keratinocytes and stimulates their lateral migration. The data presented here will demonstrate that $\alpha 7$ can also modulate the inflammatory response in skin that has been treated with croton oil.

Chemokines are another component of the inflammatory process that are crucial for the development of the appropriate response in specific tissues. This includes the skin, which has a distinct expression pattern of chemokines and their receptors (e.g., [17-19]). Chemokines are secreted basic proteins that bind to glycosaminoglycans on cell surfaces or the extracellular matrix $[19,20]$. Therefore, chemokines can be released into the circulation but also remain concentrated at specific sites of injury. Leukocytes in the bloodstream establish a loose tethering interaction with the endothelium which is mediated by selectin and integrin molecules such as E-selectin and $\alpha 4$ and $\beta 2$ integrins $[20,21]$. This initial interaction slows the responding cell (e.g., neutrophils and lymphocytes) down and allows it to roll along the endothelium where it interacts with other cell surface receptors including chemokine receptors. The adhesion of leukocytes to the endothelium then induces intracellular signaling cascades and leads to cellular reorganization and migration of the leukocyte into the target tissue $[19,20]$. Once inside the target tissue, the leukocyte will release inflammatory mediators where they in turn carry out specific functions.

This study continues the investigation of how nAChR $\alpha 7$ influences the inflammatory response through measurements of pro-inflammatory cell recruitment induced by local inflammation in the skin. To do this, croton oil was topically applied to the ear and infiltrating cells were isolated and characterized using flow cytometry. nAChR $\alpha 7 \mathrm{KO}$ mice exhibited significant increases of Ly6G positive neutrophils relative to controls $(\alpha 7 \mathrm{WT})$ at the site of inflammation. RNA analysis of both infiltrating and resident cells revealed increased IL-1 $\beta$ and IL- 6 (but not TNF $\alpha$ ) in $\alpha 7 \mathrm{KO}$ infiltrates as well as certain adhesion proteins such as ICAM1 (especially by resident cells). There was also an increase in the expression of the CCR10 chemokine receptor by infiltrating cells, as wells as an increase in the ligand for this receptor, CCL27, by resident cells. Because these chemokines are important mediators of pro-inflammatory cell recruitment to the skin, our results advance the idea that $\alpha 7$ influences inflammatory processes to include modulation of key chemokine signaling pathways.

\section{Methods}

\section{Animals}

These studies were IACUC approved. All mice were housed in a pathogen free environment with water and standard mouse chow provided ad libitum. Each experiment used groups of 3-5 mice that were age (3 to 6 months old), gender and strain matched. Wild-type (WT) and $\alpha 7 \mathrm{KO}$ mice in the $\mathrm{C} 57 \mathrm{BL} / 6$ background were initially purchased from Jackson Laboratories (Bar Harbor, ME) and subsequently maintained as a breeding colony in our animal facility. The $\alpha 7 \mathrm{KO}$ and $\alpha 7 \mathrm{WT}$ mice are routinely generated by breeding mice that are $\alpha 7 \mathrm{WT} / \mathrm{KO}$ heterozygotes to provide homozygote litter-mate mice of both $\alpha 7 \mathrm{KO}$ and $\alpha 7 \mathrm{WT}$ genotypes. The $\alpha 5$ (WT and KO) and $\beta 4$ (WT and $\mathrm{KO}$ ) mice are also maintained in breeding colonies in the University of Utah Comparative Medicine Department.

\section{Isolation of ear infiltrates}

The ears of $\alpha 7 \mathrm{WT}$ or $\alpha 7 \mathrm{KO}$ mice were treated with $10 \mu \mathrm{l}$ of croton oil (Sigma, St Louis MO), that was diluted to a final concentration of $3.5 \%$ in $4: 1$ acetone: olive oil, on each side of their ears for a total of $20 \mu \mathrm{l}$ per mouse ear. Inflammation was allowed to develop for 6 hrs before mice were sacrificed and the ears were collected. Inflamed ears were briefly dipped in $70 \%$ ethanol and PBS and separated with sterile forceps into dorsal and ventral layers. Each ear half was floated dermal side down overnight in RPMI media (Cellgro/Mediatech, Hernden, VA) supplemented with penicillin/streptomycin (Cellgro/ Mediatech, Hernden, VA) and Hepes buffer (Cellgro/ Mediatech, Hernden VA). The following day, infiltrate depleted ear halves were removed, and infiltrating cells were collected from the media. Cells were then washed with cold PBS and centrifuged at $1600 \mathrm{rpm}, 4^{\circ} \mathrm{C}$ for 10 minutes. The ear tissue depleted of infiltrating cells was frozen $\left(-80^{\circ} \mathrm{C}\right)$ and saved for RNA analysis. It should be noted that no cells were present in the media from ears of mice if an inflammatory stimulus (croton oil) was not first applied. Further, at times prior to 6 hours of croton oil exposure, minimal cells were isolated from ears making analysis of these cells difficult.

\section{Isolation of bone marrow and spleen cells}

Marrow from femurs and tibias was extracted by cutting off the ends of the bones and flushing the shaft with icecold PBS using a 25-gauge needle and 3cc syringe. The resulting mixture was passed through the needle and syringe once to obtain a single-cell suspension. Cells were centrifuged at $4^{\circ} \mathrm{C}, 1600 \mathrm{rpm}$ for 5 minutes, and then resuspended in erythrocyte lysis buffer $(0.14 \mathrm{M} \mathrm{Ammo-}$ nium Chloride, $17 \mathrm{mM}$ Tris in $\mathrm{H}_{2} \mathrm{O}$ ) for 5 minutes at $25^{\circ} \mathrm{C}$. Cells were washed with $10 \mathrm{ml}$ ice-cold PBS, centrifuged, and collected for further analysis. Similarly, spleens were 
removed and cells expressed with forceps. Single cell suspensions were then treated with ammonium chloride to lyse red blood cells, washed and collected for further analysis.

\section{Cell cytometry analysis}

To analyze cells by flow cytometry, cells were counted with a hemocytometer and 0.5 to $1 \times 10^{6}$ cells were resuspended in $1 \mathrm{ml}$ PBS, and placed into tubes on ice. For all samples, Fc receptors (Fc block, BD Bioscience Pharmingen, San Jose, CA) were blocked using $1 \mu \mathrm{g}$ per $10^{6}$ cells for 15 minutes on ice. The effectiveness of this block was tested by subsequent staining for FcR using labeled 2.4G2 antibody which routinely showed complete block. Antibodies were added to the cell samples at a concentration of $1 \mu \mathrm{g}$ per $10^{6}$ cells and incubated for 30 minutes on ice in the dark (FITC-conjugated anti-Ly6G, anti-CD45R/ B220, anti-CD4, anti-CD8 $\alpha$ from BD Bioscience Pharmingen, San Jose, CA; PE-conjugated anti-Ly6C (BD Bioscience Pharmingen, San Jose, CA), anti-CCR10 (R\&D Systems, Minneapolis, MN), anti-F4/80 from eBioscience, San Diego, CA). Isotype controls to assess nonspecific binding were FITC- or PE-conjuated rat IgG2a and PE-conjugated rat IgG2b (BD Biosciences Pharmingen, San Jose, CA). Following incubation with antibodies, cells were washed with PBS and filtered through 85 micron nylon mesh (Small Parts Company, Miami Lakes, $\mathrm{FL}$ ) to remove aggregated cells. Samples were analyzed using either a Becton Dickinson FACScan instrument or an Accuri Cell Cytometry System (Ann Arbor, Michigan). Data were analyzed with FlowJo Software (Ashland, OR). Histogram data are expressed as percentage of maximum according to standard flow cytometric analysis in which peak heights within each graph are normalized to a percentage of the peak representing the highest event number on the $\mathrm{X}$ axis. The highest event number is based on 'bins' which are numerical ranges for the parameter on the $\mathrm{X}$ axis (as described in the Flowjo.com for cell cytometry histogram generation). Data displayed as percent of Max allows for visual comparison of samples with different event numbers collected.

\section{RNA isolation for arrays and real-time PCR}

To extract RNA, cells were placed in Trizol (Invitrogen, Carlsbad CA), and processed for RNA according to the manufacturer's instructions. Ear skin (devoid of infiltrating cells) was also placed in Trizol and homogenized with a tissue tearor (Biospec Products, Bartlesville, OK). Manufacturers' directions were then followed for RNA isolation. RNA was precipitated in isopropanol and washed in $75 \%$ ethanol at room temperature. The concentration and purity of the RNA was determined with a ND-1000 Spectrophotometer (NanoDrop Technologies, Wilmington DE). A $1 \mu \mathrm{g}$ sample of each RNA was DNase treated and converted via reverse transcription PCR to cDNA (Promega, Madison WI) and used to amplify cDNA (high capacity cDNA Archive Kit, Applied BioSystems, Foster City CA). 20 ng of cDNA was loaded into each well and the following TaqMan Gene Expression Assays were used: ICAM1 (Mm00526023_m1), Itga3 (Mm0042890_m1), Itgb2 (Mm00434513_m1), E-Selectin (Mm00441278_m1), IL1- $\beta$ (Mm00434228_m1), IL-6 (Mm00446190_m1), TNF $\alpha$ (Mm00443258_m1), CXCL1 (Mm00433859_m1), CXCL5 (Mm00436451_g1), CXCL9 (Mm0043494_m1), CCL1 (Mm00441236_m1), CCL2 (Mm00441242_m1), CCL3 (Mm00441258_m1), CCL4 (Mm00443111_m1), CCL5 (Mm01302427_m1), CCL11 (Mm00441238_m1), CCL27 (Mm00441257), CCL28 (Mm00445039_m1), GAPDH (4352339E), $\beta$-actin (4352341E) (Applied Biosystems, Foster City CA). GAPDH and $\beta$-actin were used as internal control genes, and all samples were run in duplicate. Fold-changes in RNA expression were calculated relative to RNA from matched control animals, and was determined using the comparative Ct method (Applied Biosystems). RNA from both skin tissue and infiltrating cells was also analyzed in duplicate using Mouse Inflammatory Cytokines and Receptors $\mathrm{RT}^{2}$ Profiler PCR Arrays (SABiosciences, Mouse Inflammatory Cytokines and Receptors, PAMM011E) according to manufacturers' directions. Briefly, RNA was converted to cDNA using the RT ${ }^{2}$ First Strand Kit, and amplified using $\mathrm{RT}^{2}$ SYBR green/ROX qPCR master mix (SABiosciences, Frederick, MD). WT transcript levels for each experiment were normalized to a value of 1 to allow generation of fold change values in the alpha7KO in each experiment, and to compare fold change with the $\mathrm{KO}$ between experiments. Error bars reflect the standard error of the mean as calculated from 3 independent experiments with 5-6 mice per experimental group.

\section{Results}

\section{Infiltration of pro-inflammatory cells is modified by a7} expression

The mouse ear pinna provides a unique site to study cellular infiltration following skin inflammation. This is due to the distinct dorsal and ventral sides, each with an epidermal and dermal layer, that are separated by auricular cartilage. Upon application of an inflammatory agent, cells collect between the dorsal and ventral ear skin and infiltrate the tissue. The infiltrating cells are recovered from the media after mechanical separation of the ear into the respective halves, and overnight incubation of the ear halves in media allows cells to be released into the media. This procedure results in the isolation of recruited cells without using more disruptive interventions that can inconsistently impact upon cells more sensitive to harsh isolation conditions. To examine an inflammatory 
response in the skin, we used the well-characterized method of topical application of croton oil, an organic phorbol compound derived from the seeds of the Croton tiglium tree. A particular advantage of this method is the relatively mild inflammatory response which could facilitate detection of $\alpha 7$ modulatory components. Mouse ears were treated with topically applied $3.5 \%$ croton oil to induce local inflammation. At six hours post croton oil application, the mice (groups of $5 \alpha 7 \mathrm{WT}$ or $\alpha 7 \mathrm{KO}$ ) were sacrificed and the ears removed. The dorsal and ventral sides of the ear were separated and incubated overnight in media (see Methods). The results presented in Figure 1 a show that the total number of cells isolated from $\alpha 7 \mathrm{KO}$ mice is significantly $(\mathrm{p}<0.01)$ enhanced relative to wildtype mice. Cell numbers reflect the total number of cells obtained from 5 mice in each group. The standard error of the mean is derived by averaging the number of cells obtained from each of these groups (WT or KO) from at least 5 separated experiments. In the absence of an inflammatory stimulus such as croton oil, there are too few cells to isolate and characterize. Further, we have found that the overnight incubation of the ear halves is required to obtain the infiltrating cells suggesting that the cells are not just in the edematous fluid of the ear.

To determine if infiltrating cells from $\alpha 7 \mathrm{WT}$ and $\alpha 7 \mathrm{KO}$ mice differ in cytokine production, quantitative real-time PCR (qPCR) of key pro-inflammatory cytokine RNAs was done using Taqman gene expression assays. The cytokines examined were previously shown to differ between $\mathrm{WT}$ and $\mathrm{KO}$ mice upon ultraviolet radiation exposure to defined skin sites [8]. There was greater IL$1 \beta$ and IL- $6(\mathrm{p}<0.05)$ in the $\alpha 7 \mathrm{KO}$ cells relative to infiltrating cells from the $\alpha 7 \mathrm{WT}$ mouse (Figure 1b). However, other cytokine RNA expression such as for TNFa, while elevated in the $\alpha 7 \mathrm{KO}$ infiltrates, was not statistically different between genotypes. In the ear tissue remaining after depletion of infiltrating cells the expression of IL-1 $\beta$, IL- 6 or TNF $\alpha$ RNA did not differ between $\alpha 7 \mathrm{WT}$ and $\alpha 7 \mathrm{KO}$ mice (Figure 1c). There was, however, a substantial decrease in TNF $\alpha$ in the ear skin of both the $\alpha 7 \mathrm{WT}$ and $\alpha 7 \mathrm{KO}$ mice treated with croton oil. Thus in skin receiving croton oil there is an overall increase in the number of cells recruited to the site of inflammation in the $\alpha 7 \mathrm{KO}$ mouse relative to $\alpha 7 \mathrm{WT}$. Infiltrating cells have elevated IL- $1 \beta$ and IL- 6 message in the $\alpha 7 \mathrm{KO}$ compared to WT animals while the resident skin cells of the WT and KO mice express equivalent amounts of these cytokines.

\section{Neutrophil infiltration to the site of skin inflammation is enhanced in the a7KO mouse}

The identity of the infiltrating cells at the site of inflammation following croton oil application was determined using flow cytometry and markers specific for neutrophils (Ly6G; PMNs: polymorphonuclear cells), mature macrophages (F4/80; [22]), B-cells (B220) and T-cells (helper T-cells, CD4 or cytotoxic T-cells, CD8). As shown in Figure 2, there was a dramatic difference in infiltration by neutrophils to the site of inflammation in the $\alpha 7 \mathrm{KO}$ when compared to the $\alpha 7 \mathrm{WT}$ (Figure 2a). Staining with an isotype (FITC-IgG2a) control for the anti-Ly6G antibody resulted in a histogram that is identical to the unstained controls (data not shown). Results are expressed as percentage of the maximum response and percent of Ly6G positive cells is reflected by the percentage above the peak response ( $\alpha 7 \mathrm{KO}, 54 \%$; $\alpha 7 \mathrm{WT} 33.6$ percent neutrophils). The increase in $\mathrm{Ly}^{6} \mathrm{G}^{+}$cells in the $\alpha 7 \mathrm{KO}$ is also observed in $\alpha 7 \mathrm{KO}$ mice that are in the $\mathrm{C} 3 \mathrm{H}$ background (not shown) indicating that while B6 and $\mathrm{C} 3 \mathrm{H}$ mouse strains may differ substantially in response to nicotine (e.g., see [2]), the results measured here are independent of mouse strain backgrounds. The increase in PMNs recruited in the $\alpha 7 \mathrm{KO}$ mouse was consistently measured using either the anti-Ly6G antibody or antiLy6C antibody (which detects PMNs as well as other granulocytes, as in Figure 2c). The small difference in intensity of staining with F4/80, B220, or CD4 antibodies was not consistently observed, nor was the small decrease in intensity of staining with the anti-CD8 antibody (Figure $2 \mathrm{~b}$ ). The possibility that increased PMN recruitment in the $\alpha 7 \mathrm{KO}$ mouse is representative of a difference in the composition of bone marrow in the $\alpha 7 \mathrm{KO}$ mouse was examined. Bone marrow was extracted from mice of each genotype and antibodies to cell type specific markers were used to determine the percentage of neutrophils, macrophages and B cells. The results shown in Figure 2c show no difference between $\alpha 7 \mathrm{WT}$ and $\alpha 7 \mathrm{KO}$ mice in number of $\mathrm{Ly}^{6} \mathrm{G}^{+}$neutrophils or Ly6 $\mathrm{C}^{+}$granulocytes or other cell types (not shown) in the bone marrow. Further, the spleen, while not a major site of neutrophil residence or source for recruitment, also showed no difference in neutrophils the between WT and KO mice.

Because nicotinic receptors such as $\alpha 5$ and $\beta 4$ are also expressed in peripheral systems (especially in ganglia; [1]), the specificity of the influence of $\alpha 7$ on enhanced neutrophil infiltration was examined. As described above, croton oil was applied to ears of mice having either the $n A C h R \alpha 5$ or $n A C h R \beta 4$ subunit ablated $(\alpha 5 \mathrm{KO}$ or $\beta 4 \mathrm{KO}$, respectively). The $\alpha 5 \mathrm{KO}$ was selected because the absence of expression by this subunit has been implicated in altering the course of other inflammatory-related diseases [23] and in some cases it has been suggested to interact with $\alpha 7$ to form heteromeric receptors with functional differences uniquely distinct from $\alpha 7$ homomeric receptors [1]. The $\beta 4$ subunit is the principal beta subunit of nAChRs in peripheral nerve tissue such as autonomic ganglia [1]. Further, while mice tolerate ablation of $\beta 4$, presumably due to compensation by the $\beta 2$ subunit, the function of the receptor and response to external agents 


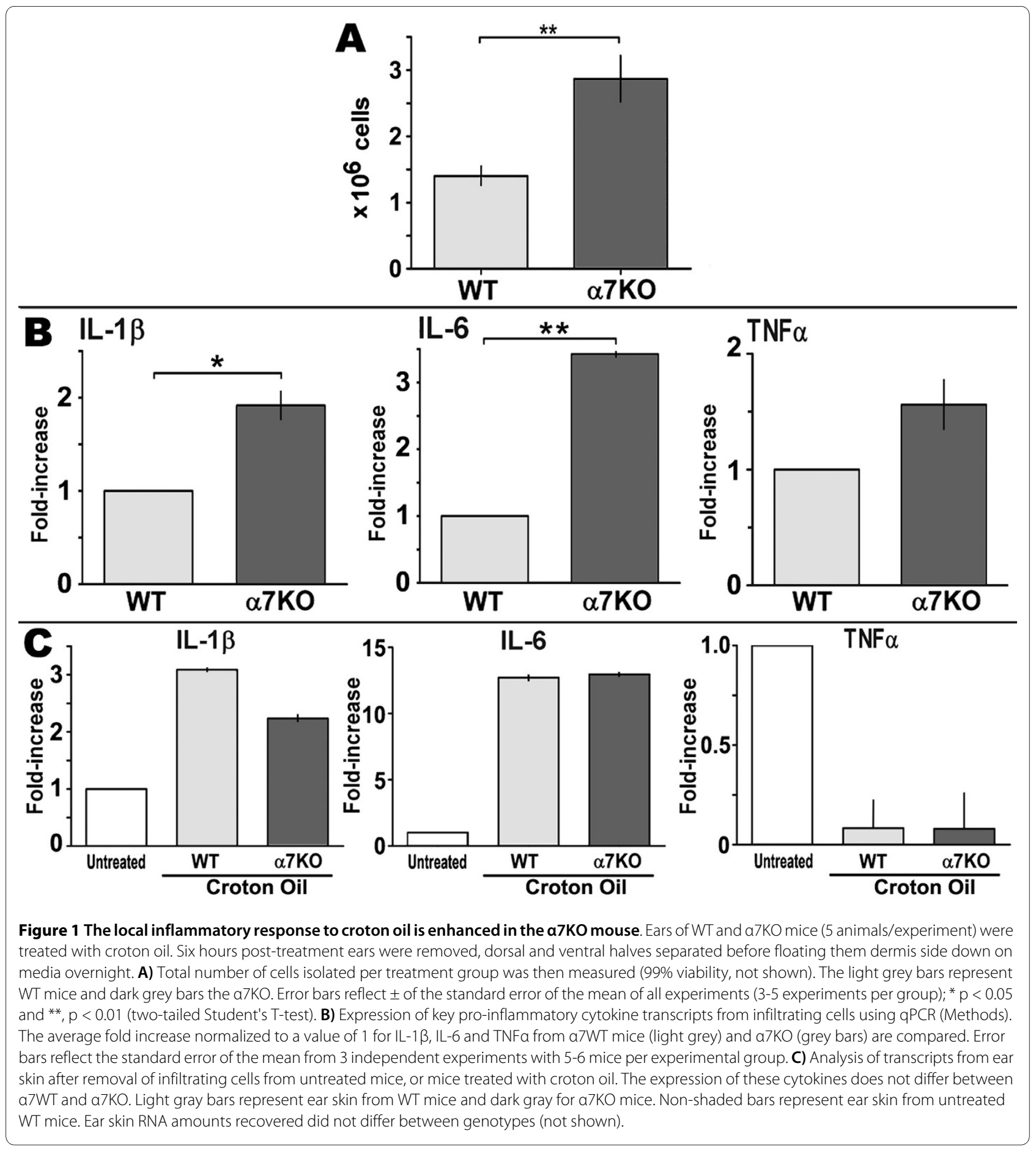

such as nicotine is significantly altered [24,25]. Neither subunit forms a functional receptor when expressed alone [1]. As shown for neutrophil skin infiltrates in Figure $2 \mathrm{~d}$, no difference was observed for either of the $\alpha 5 \mathrm{KO}$ or the $\beta 4 \mathrm{KO}$ mice relative to appropriately matched WT litter-mate controls. Further, neither the $\alpha 5 \mathrm{KO}$ nor the $\beta 4 \mathrm{KO}$ exhibit any other difference in cellular infiltration, such as macrophages or lymphocytes (not shown). Thus, the effects related to $\alpha 7$ expression are not the result of a more broad disruption of nAChRs expressed in ganglia or other peripheral sites or of non-specific genetic manipulations used to generate these mice.

To determine whether the increase in neutrophils in the inflamed ear of the $\alpha 7 \mathrm{KO}$ mouse persists at later time points, ears were harvested 24 hours after croton oil application. Results obtained indicate that no difference 


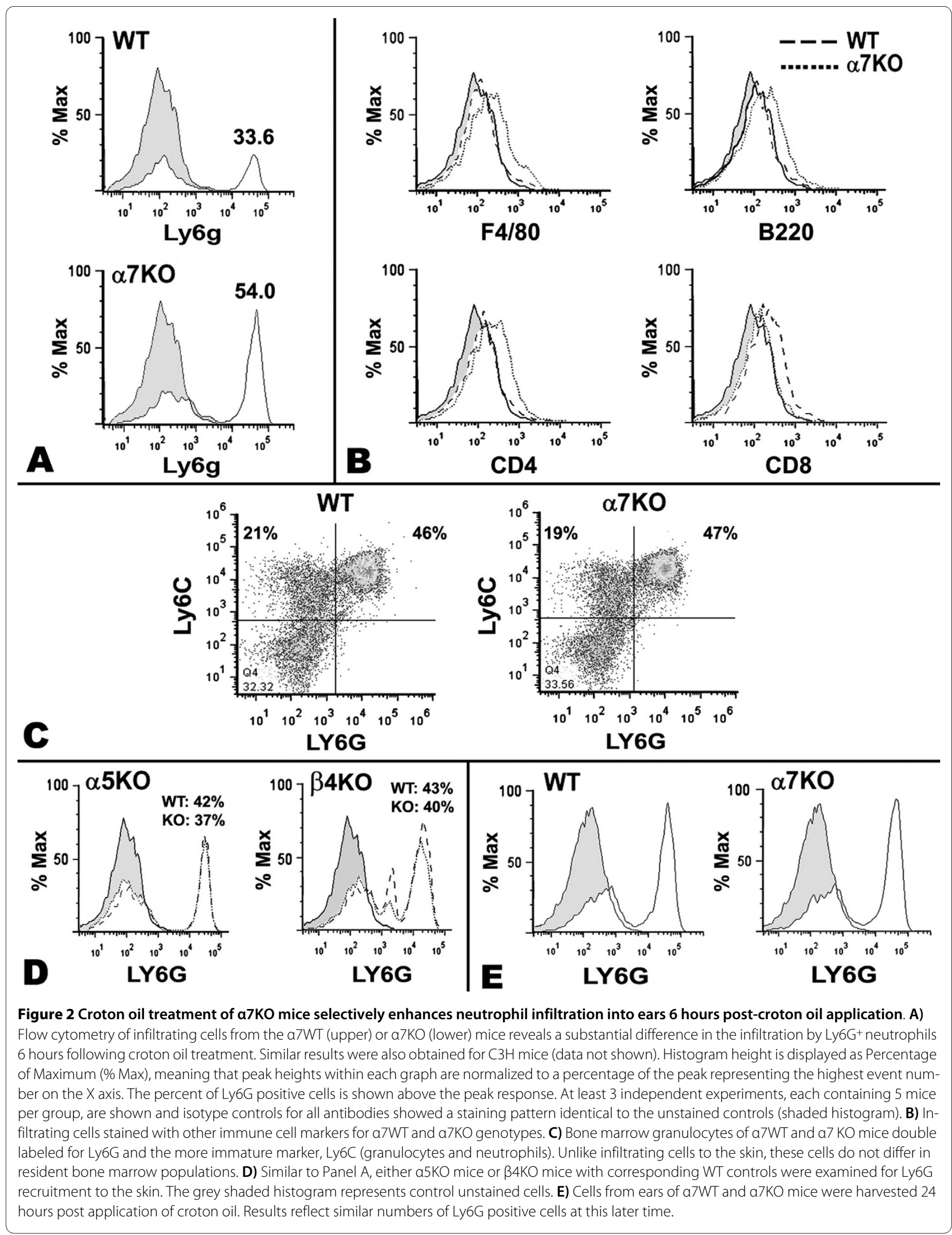


in the number of neutrophils (or macrophages and lymphocyte populations, Figure 2e) was observed between the $\alpha 7 \mathrm{WT}$ and the $\alpha 7 \mathrm{KO}$ mice. Thus, the absence of $\alpha 7$ appears to enhance the early response to an inflammatory agent while not affecting neutrophil accumulation at later times ( $24 \mathrm{hrs}$, discussed in the next section).

\section{Chemokine expression differs in cells infiltrating the skin of a7KO mice}

Cytokines and chemokines play a key role in normal cellular trafficking and recruitment of cells to sites of inflammation [11,19,20,26,27]. Both chemokine and chemokine receptor expression is especially important to rapid responses to assure cells are directed to the appropriate tissue sites. We determined the impact of $\alpha 7$ on chemokine and chemokine receptor expression by the infiltrating cell population. In the same experimental paradigm as above, infiltrating cells were harvested from ears of $\alpha 7 \mathrm{WT}$ or $\alpha 7 \mathrm{KO}$ mice after exposure to croton oil for 6 hours. The RNA from these cells was analyzed using commercially available microarray systems (SABiosystems, see Methods) for cytokines, chemokines and chemokine receptors. While the majority of the examined signaling molecules did not vary between mice of differing genotypes ( $\alpha 7 \mathrm{WT}$ vs. $\alpha 7 \mathrm{KO})$, there were prominent differences (Figure 3a). Among the most notable was the expression of the chemokine receptor CCR10 where expression was much greater in the $\alpha 7 \mathrm{KO}$ infiltrating cells. This result was verified using qPCR (Applied Biosciences TaqMan primers) as shown in Figure 3b. CCR10 message was not detected in the skin of either the $\alpha 7 \mathrm{WT}$ or $\alpha 7 \mathrm{KO}$ mouse (not shown).

Although signaling through the CCR10 chemokine receptor is most often associated with lymphocytes rather than neutrophils (discussed in next section), the possibility that the expression of the ligand for this receptor was also dysregulated was examined. This was done independently of the arrays since the chemokine ligands for CCR10, CCL27 and CCL28, were not included in the arrays. Therefore, we measured CCL27 and CCL28 in RNA from both infiltrating cells and resident skin of the inflamed ear using TaqMan probes and qPCR. Neither CCL27 nor CCL28 were detected in the RNA from infiltrating cells of either the $\alpha 7 \mathrm{WT}$ or $\alpha 7 \mathrm{KO}$ mice (not shown). This was not unexpected since the expression of these ligands would be anticipated to be expressed by resident cells at the site of the inflammatory stimulation in order to recruit inflammatory cells. CCL27 in resident cell RNA was detected and its expression was elevated in the croton-oil exposed skin of the $\alpha 7 \mathrm{KO}$ compared to the $\alpha 7 \mathrm{WT}$ mouse (Figure 3c).

\section{Identity of CCR10 positive infiltrating cells}

Because CCR10 expression is most often associated with lymphocytes [28-30], the identity of CCR10 expressing cells in the cellular infiltrates of croton oil treated mice was examined. To determine if the infiltrating neutrophils described above were CCR10 positive, cells isolated from animals $(\alpha 7 \mathrm{WT}$ and $\alpha 7 \mathrm{KO})$ were co-labeled for Ly6G and CCR10. As measured using flow cytometry, Ly6G+ infiltrating cells were substantially increased in $\alpha 7 \mathrm{KO}$ mice $(47 \%$ in the $\alpha 7 \mathrm{KO}$ vs. $26 \%$ in $\alpha 7 \mathrm{WT}$, Figure 4a). Further, this difference was also reflected in the number of $\mathrm{Ly} 6 \mathrm{G}^{+}$cells expressing CCR10 (32\% in $\alpha 7 \mathrm{KO}$ vs. $18 \%$ in $\alpha 7 \mathrm{WT})$. However, the intensity of CCR10 staining of these neutrophils is less than that observed for CCR10 positive cells of the bone marrow or spleen (Figure 4a). We refer to the skin associated infiltrating neutrophils as Ly6G ${ }^{+} \mathrm{CCR} 10^{\mathrm{lo}}$. Results in Figure 4a also show that the majority of bone marrow cells that are $\mathrm{Ly} 6 \mathrm{G}^{+}$are not CCR10 positive (but $\mathrm{Ly}_{6 \mathrm{G}}{ }^{+} \mathrm{CCR} 10^{+}$cells are definitely present) and the majority of CCR $10^{+}$cells in the spleen are not $\mathrm{Ly}_{6 \mathrm{G}}$, but there is a large population of Ly6G ${ }^{\text {neg CCR } 10 h i c e l l s . ~ D i f f e r e n c e s ~ i n ~ t h e ~ n u m b e r ~ o f ~}$ CCR10 positive cells between $\alpha 7 \mathrm{WT}$ and $\alpha 7 \mathrm{KO}$ in the bone marrow or spleen were not observed. Therefore, these results suggest a novel population of CCR $10^{\text {lo }}$ neutrophils that are recruited to the skin. The $\beta 4 \mathrm{KO}$ skin infiltrate cells were also examined for the presence of Ly $6 \mathrm{G}+\mathrm{CCR} 10^{\text {lo }}$ cells (Figure $4 \mathrm{~b}$ ). The results demonstrate that $\mathrm{Ly} 6 \mathrm{G}^{+} \mathrm{CCR} 10^{\text {lo }}$ cells constitute the majority of the infiltrating population of cells but no difference between the $\beta 4 \mathrm{WT}$ and $\beta 4 \mathrm{KO}$ in percentage of these cells is observed. This result again points to the specificity of the enhanced response in the $\alpha 7 \mathrm{KO}$ mouse.

Finally, we tested whether other immune cells infiltrating the skin were CCR10 positive in the $\alpha 7 \mathrm{KO}$ mouse. For these measurements, cells (including T-cells, B-cells and macrophages) collected from ears 6 hours post-inflammatory challenge were co-labeled with CCR10 and quantitated using flow cytometry analysis. As shown in Figure $4 \mathrm{c}$, the difference between the $\alpha 7 \mathrm{KO}$ and $\alpha 7 \mathrm{WT}$ mice in CCR $10^{\text {lo }}$ cells is present (as shown in Figure 4a) and these $\mathrm{CCR} 10^{\text {lo }}$ staining cells are $\mathrm{F} 480^{\text {neg }} \mathrm{B} 220^{\text {neg }} \mathrm{CD} 4^{\text {neg }} \mathrm{CD} 8^{\text {neg }}$. Thus, croton oil challenge to the $\alpha 7 \mathrm{KO}$ mouse results in a greater number of $\mathrm{Ly}_{6 \mathrm{G}} \mathrm{CCCR}^{+} 10^{\mathrm{lo}}$, as compared to the $\alpha 7 \mathrm{WT}$ mouse, at the site of inflammation.

\section{Other factors affecting cellular trafficking}

Integrins and adhesion proteins also play a central role in the proper trafficking and accumulation of cells at sites of inflammation. The change in transcript expression of some adhesion proteins including ICAM1, integrins $\alpha 3$ (Itga3) and $\beta 2$ (Itgb2), and E-selectin were measured and are shown in Figure 5. The results show that E-selection (CD62E), which is normally present on endothelial cells, is increased in the skin (resident cells) of the $\alpha 7 \mathrm{KO}$ mouse relative to the $\alpha 7 \mathrm{WT}$ animal (Figure 5, bottom panel) and is not detectable in the infiltrating cells (not 


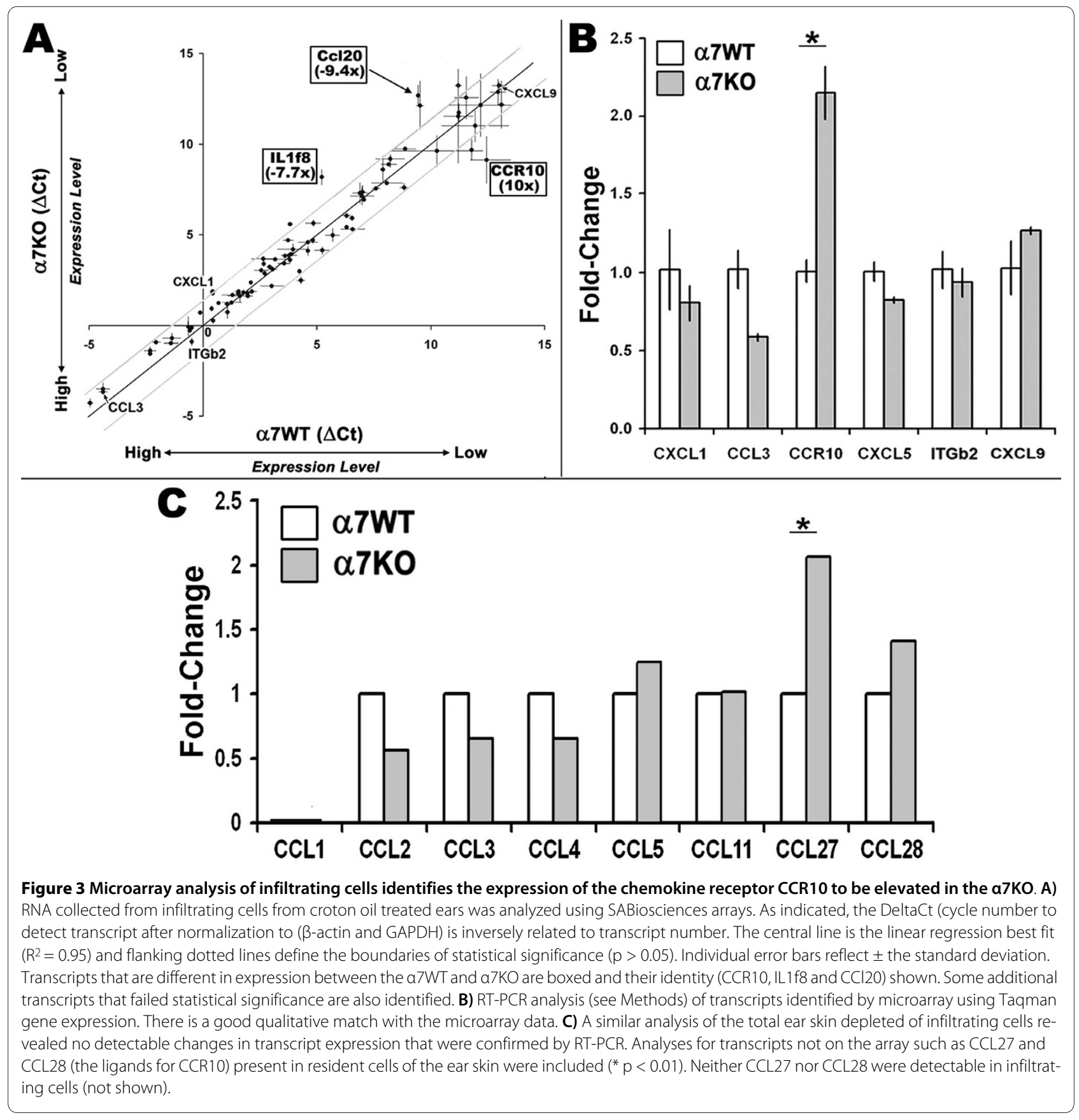

shown). In infiltrating cells the $\alpha 3$ integrin Itga3 was elevated in the $\alpha 7 \mathrm{KO}$ mouse but not in the resident tissue of $\alpha 7 \mathrm{KO}$ mice where expression did not differ from the $\alpha 7 \mathrm{WT}$. The $\beta 2$ integrin expression did not differ between $\alpha 7 \mathrm{WT}$ and $\alpha 7 \mathrm{KO}$ (not shown). ICAM-1 (CD54), which can be expressed on a variety of cells including hematopoietic cells and resident cells such as fibroblasts and keratinocytes, is elevated in both the infiltrating cells and the resident tissue of the $\alpha 7 \mathrm{KO}$ mouse. Therefore, selective differences in the expression of adhesion molecules and chemokines are observed in the $\alpha 7 \mathrm{KO}$ mouse that could account for the increase in PMN recruitment and accumulation to sites of inflammation.

\section{Discussion}

The skin is a site of frequent but localized pro-inflammatory events. The rapid onset of local inflammatory processes includes elevated cytokine and chemokine production as well as cellular infiltration. Nicotinic acetylcholine receptors ( $\mathrm{AAChR}$ ), while best characterized as neurotransmitter receptors on neurons, also contribute to host defenses in many tissues, including the skin, 


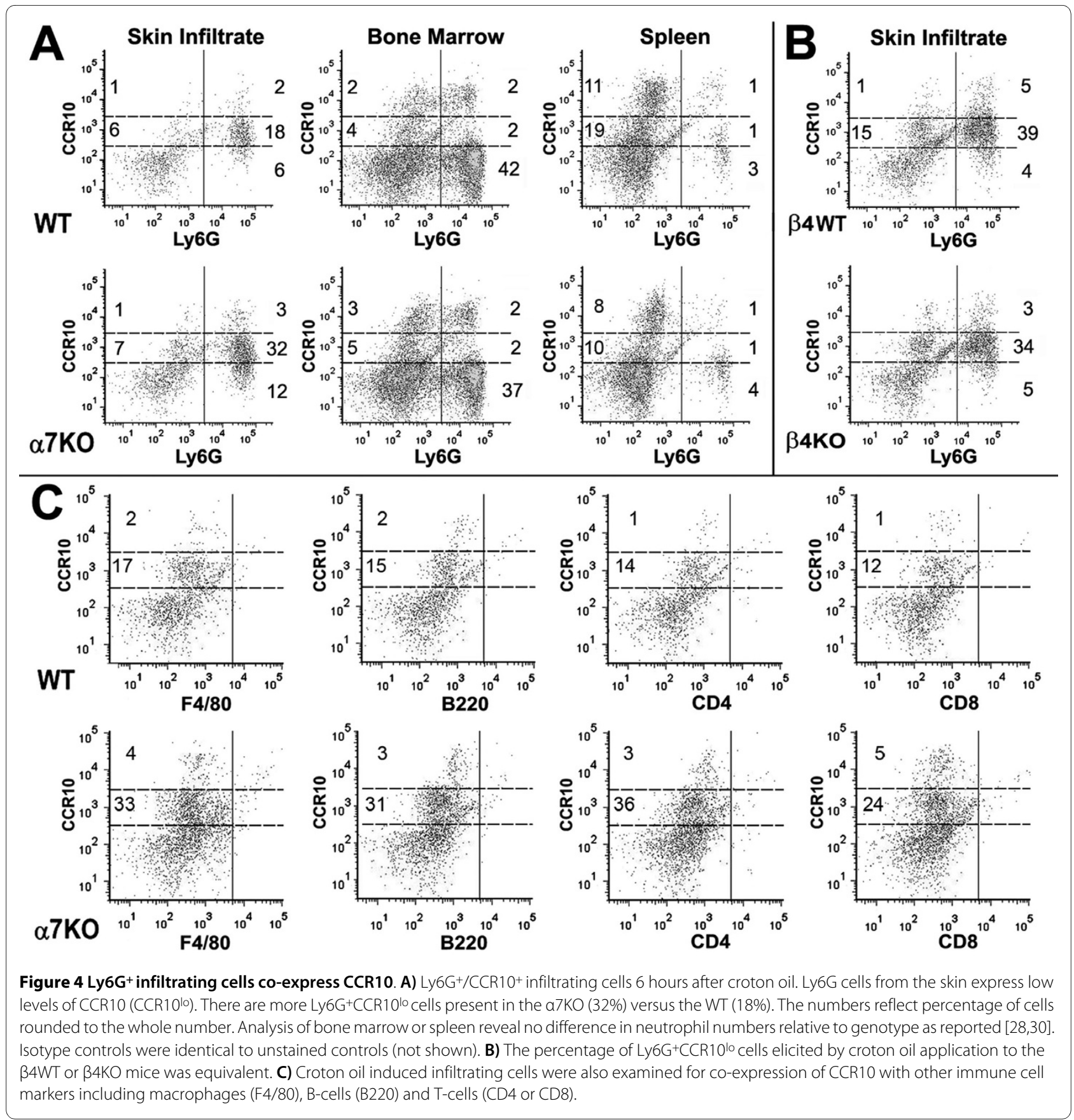

through mechanisms not necessarily associated with the more recognized role in modulating neurotransmission [1-3,6,31]. A prominent nAChR composed of the $\alpha 7$ subunit, as well as its endogenous agonists acetylcholine and choline, are expressed by keratinocytes $[6,32,33]$. The status of acetylcholine production by cells in the skin, other than keratinocytes and especially in the context of the inflammatory response, remains to be fully explored. The nAChRs are also responsive to the exogenous agonist, nicotine. Much of what we know about the role of this receptor in inflammation has been found through exam- ining cultured cell systems or the mouse model (especially mice lacking $\alpha 7$ expression, $\alpha 7 \mathrm{KO})$. Many studies have demonstrated that in the absence of $\alpha 7$, the response to inflammatory stimuli is elevated. This includes the influence of $\alpha 7$ on inflammatory pro-inflammatory cytokine signaling (e.g., TNF $\alpha$ [7]), damped inflammatory cytokine expression by macrophages (see [34] but also see [35]), altered subsequent adaptive immune responses including antibody production [36], and shifts in inflammatory responses in tissues receiving vagal nerve innervation [34,37]. In the lung, an influence by $\alpha 7$ 


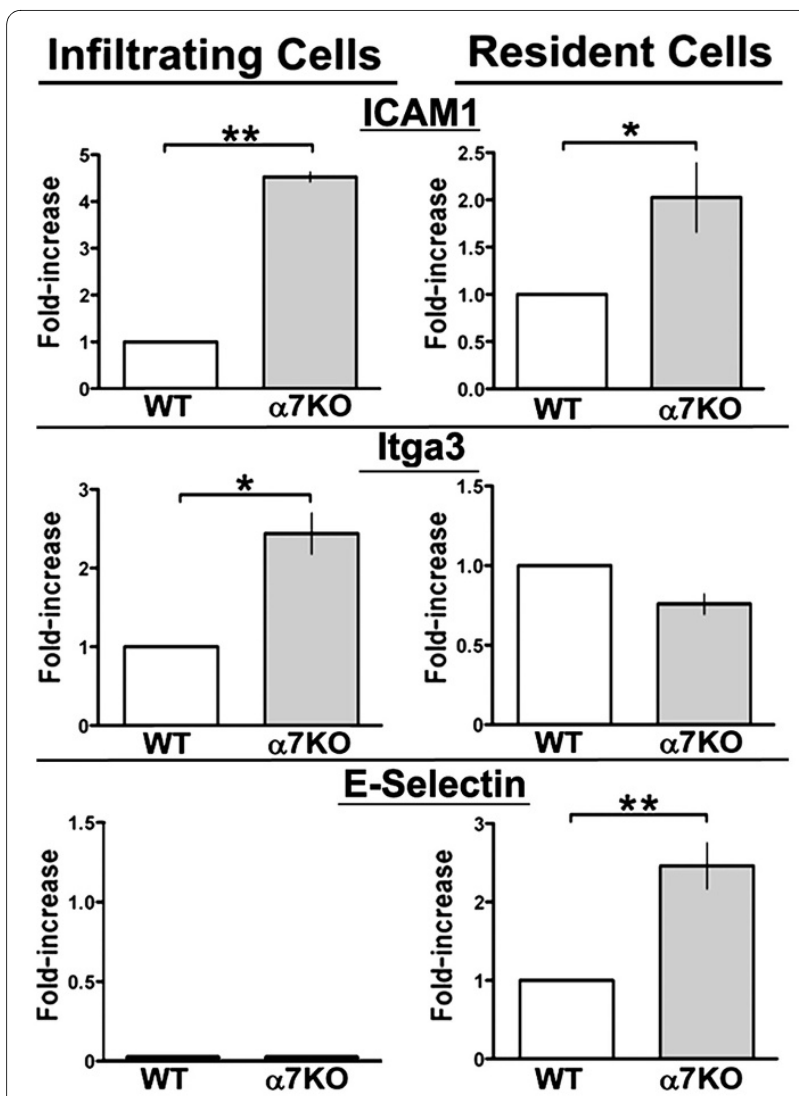

Figure 5 The expression of adhesion molecule transcripts is altered by $\alpha 7$ expression. Examination of infiltrating cells and resident cells after croton oil treatment for 6 hours reveals that certain molecules important to cell recruitment and localization to inflamed tissue are expressed. As shown using QPCR, in a7KO mice transcripts for ICAM1 are enhanced considerably in infiltrating cells and to a lesser extent in resident cells relative to controls (WT mice values normalized to 1 were used to determine fold increase observed in the KO). Itga3 transcripts are increased in a7KO infiltrating cells. In contrast, E-selectin transcripts are elevated in resident cells (ear skin depleted of infiltrating cells) and especially in the a $7 \mathrm{KO}$, but these transcripts were not detected in infiltrating cells. Error bars represent standard error of the mean; ${ }^{*} p<0.05 ;{ }^{* *} p<0.01$

on acid-induced acute lung injury in the mouse model is observed and includes elicitation of more inflammatory cytokines in the $\alpha 7 \mathrm{KO}$ over the $\alpha 7 \mathrm{WT}$ animals [38]. This increase in lung inflammatory cytokines in the $\alpha 7 \mathrm{KO}$ mice is associated with more severe lung injury than the WT mice suggesting that this receptor plays a regulatory role in balancing the inflammatory processes in the lung. In a previous report [8] we demonstrated that $\alpha 7 \mathrm{KO}$ mice elicit a greater response to a common environmental inflammatory agent, ultraviolet radiation (UVR). The skin does not receive significant parasympathetic or any vagal innervation indicating that these neuronal systems are not directly required for $\alpha 7$ to impact on these processes. A more local control of signaling is also supported by studies examining keratinocytes cultured in vitro which express nAChRs, including $\alpha 7$, and these impact upon multiple cellular processes including cell migration and the expression of various chemokines and adhesion molecules [39-43]. Thus, it can be hypothesized that the role of $\alpha 7$ in normal inflammatory responses in the skin are likely responsive to acetylcholine or choline and suggest that the normal physiologic function of this nAChR in regulating inflammation is customized according to tissue, cell type and neuronal complexity.

In this report the lack of $\alpha 7$ was found to modifying cellular infiltration to a local inflammatory stimulus of the skin. As reported previously, the lack of $\alpha 7$ expression ( $\alpha 7 \mathrm{KO}$ mice) corresponds with modulation of proinflammatory molecules such as IL- $1 \beta$ and IL-6 $[7,8,44]$. We now find this includes an early enhancement of neutrophil infiltration to an inflamed area of the skin that is not due to increased numbers of available neutrophils in the bone marrow or spleen of the $\alpha 7 \mathrm{KO}$ mouse. Consistent with altered recruitment of neutrophils is a coincident increase in expression by the $\alpha 7 \mathrm{KO}$ mouse of the skin-associated signaling chemokine, CCL27, and its receptor (CCR10) that is expressed by responding infiltrating cells. This is significant in terms of identifying potential specific contributors in these interactions. The chemokine system, consisting of four gene families distinguished by the position of their cysteine residues $[19,20]$, is complicated by the considerable promiscuity in ligand-receptor interactions and tissue diversity in expression (for detailed review see [19]). In general, lymphocytes are reported to express predominantly CCR receptors that interact with $\mathrm{CC}$ chemokines. In contrast, neutrophils express predominantly CXCR receptors that interact with the CXC chemokines. Recruitment of cells to the skin through elicitation by CCL27 is not unexpected since this chemokine is known to be induced by specific skin-inflammatory cell interactions [28-30]. However, CCR10 expression by neutrophils has to our knowledge not been reported. Our results find that the neutrophils, as defined by Ly6G (and co-expression of Ly6C) expression, are recruited in both the $\alpha 7 \mathrm{WT}$ and the $\alpha 7 \mathrm{KO}$ mouse and these cells also exhibit CCR10 expression. The skin infiltrating cells from the $\alpha 7 \mathrm{KO}$ mice also express elevated RNA transcripts for this chemokine receptor. Notably, the majority of the infiltrating Ly6G+ neutrophils were CCR10 positive but stained less intensely for this marker than neutrophils in the bone marrow or spleen. Further, in the bone marrow and spleen the majority of CCR10 positive cells are not Ly6G+. The significance of this population of neutrophils in the skin and their characterization as $\mathrm{Ly} 6 \mathrm{G}^{+} \mathrm{CCR} 10^{\text {lo }}$ remains to be investigated further. A recent report [45] showing that $\alpha 7 \mathrm{KO}$ mice elicit an accelerated clearance of $E$. coli injected into the peritoneum of mice through a more rapid recruitment of neutrophils to the site of infec- 
tion suggests that these findings could be more generalized to include sites other than the skin. However, it is noteworthy that the impact by $\alpha 7 \mathrm{KO}$ on bacterial clearance was transient during the early phase of bacterial infection [45]. Our results are consistent with the role of $\alpha 7$ being most important early in an inflammatory response where it appears to limit (or in the case of the $\alpha 7 \mathrm{KO}$ enhance) the magnitude of initiating events. This in turn would correspond with control of greater tissue damage as has been suggested from studies of lung responses in $\alpha 7 \mathrm{KO}$ mice [38] and our report that the skin of the $\alpha 7 \mathrm{KO}$ mouse demonstrates greater edema and thickness following ultraviolet radiation of back skin [8].

Another alteration in $\alpha 7 \mathrm{KO}$ mice is a change in the expression of adhesion molecules in both the target tissue and the trafficking cells. The specificity of the expression of adhesion molecules by either infiltrating cells (e.g., Itga3 in Figure 5) or resident cells (e.g., E-selectin Figure $5)$ is also notable. This suggests that $\alpha 7$ expression in the skin influences multiple mechanisms downstream of receptor activation including shifts in cytokines and chemokines that will subsequently have a broad effect on many cells in the environment regardless of their $\alpha 7$ expression status.

The presence of sustained nicotine exposure, which impacts all nAChRs, would likely introduce an imbalance to cellular pathways, of which $\alpha 7$ is a modulatory component. Similar to neurological systems where imbalance in nAChR expression leads to phenotypes of addiction [1], the interaction between nAChRs and pro-inflammatory systems is also finely balanced. For example, it has been reported that acne and eczema are more common in nonsmokers suggesting that nicotine may actually dampen specific inflammatory responses in the skin leading to these diseases [46,47]; Or, such responses may reflect an altered 'tone', perhaps demonstrated by elevated baseline levels of inflammatory cytokines. This is not inconsistent with the calming effects of nicotine on the inflammatory bowel disease ulcerative colitis (UC) and where cessation of smoking correlates with an induced flare in this disease (see [3]). However, nicotine exacerbates Crohns disease [48-52], a related inflammatory bowel disease of different pathology. That the active compound is nicotine has been demonstrated many times with delivery of this compound through patches placed on rats, mice and in some cases humans and appears to reverse some inflammatory symptoms while exacerbating others [53,54]. These interesting associations again point to the fact that we have much to learn about $n A C h R$ regulation of inflammation in different tissues whose mechanism(s) reflect a summation of the impact by multiple nAChRs and intracellular signaling systems. Further, smoking is associated with premature aging of skin which may be a result of nicotine effects on the normal responses of the nicotinic receptors in this tissue.

\section{Conclusion}

This study finds that mice lacking $\mathrm{nAChR} \alpha \mathrm{7}$ have elevated levels of neutrophils in the skin following topical application of a skin irritant. The $\alpha 7 \mathrm{KO}$ mice, independent of the mouse strain backgrounds tested, have elevated inflammatory cytokines (IL-1 $\beta$ and IL- 6 , but not necessarily TNF $\alpha$ ) and increased expression of adhesion molecules and chemokines that are important to recruitment of the pro-inflammatory cells to the skin. One challenge remaining will be to determine if such regulatory interactions among $\mathrm{nAChR}$ and inflammatory systems are equally customized to the microenvironment of other organs such as gut, secondary lymphoid organs, as well as the brain.

\section{Abbreviations}

nAChR: neuronal nicotinic acetylcholine receptor; IL: interleukin; TNF: tumor necrosis factor; qPCR: quantitative PCR.

\section{Competing interests}

The authors declare that they have no competing interests.

\section{Authors' contributions}

LCG and SWR designed the experiments, analyzed the data, and wrote the manuscript.

AVO initiated the study, implemented techniques, analyzed data, and contributed to the writing. MR contributed technical expertise and analysis of data as well as provided editing of the manuscript. All of the authors have read and approved the final version of the manuscript.

\section{Acknowledgements}

This research was supported by grants from the NIH (DA025057 and AG029838 to LCG for supplies and salaries; DA025057 and AG017517 to SWR for supplies and salaries), a VA Merit grant (LCG, for supplies) and by the Browning Foundation of Utah in support of graduate education.

\section{Author Details}

${ }^{1}$ Geriatric Research, Education and Clinical Center, Salt Lake City VA Medical Center, USA, ${ }^{2}$ Division of Geriatrics, Department of Internal Medicine, University of Utah School of Medicine, Salt Lake City, UT, USA, ${ }^{3}$ Department of Pathology, University of Utah School of Medicine, Salt Lake City, UT, USA and ${ }^{4}$ Department of Neurobiology and Anatomy, University of Utah School of Medicine, Salt Lake City, UT, USA

Received: 6 May 2010 Accepted: 12 July 2010

Published: 12 July 2010

\section{References}

1. Albuquerque EX, Pereira EF, Alkondon M, Rogers SW: Mammalian nicotinic acetylcholine receptors: from structure to function. Physiol Rev 2009 89:73-120

2. Rogers S, Gould TJ, Baker TB: Mouse Models and the Genetics of Nicotine Addiction. In Phenotypes and Endophenotypes: Foundations for Genetic Studies of Nicotine Use and Dependence Volume 20. National Cancer Institute Tobacco Control Monograph 20; 2009:133-173.

3. Gahring LC, Rogers SW: Neuronal Nicotinic Acetylcholine Receptor Expression and Function on Non-Neuronal Cells. The AAPS Journal 2005, 7:E885-E894.

4. Wessler I, Kilbinger $\mathrm{H}$, Bittinger $\mathrm{F}$, Unger R, Kirkpatrick CJ: The nonneuronal cholinergic system in humans: expression, function and pathophysiology. Life Sci 2003, 72:2055-2061. 
5. Gallowitsch-Puerta M, Tracey KJ: Immunologic role of the cholinergic anti-inflammatory pathway and the nicotinic acetylcholine alpha 7 receptor. Ann N Y Acad Sci 2005, 1062:209-219.

6. de Jonge WJ, Ulloa L: The alpha7 nicotinic acetylcholine receptor as a pharmacological target for inflammation. BrJ Pharmacol 2007, 151:915-929.

7. Carlson NG, Bacchi A, Rogers SW, Gahring LC: Nicotine blocks TNF-alphamediated neuroprotection to NMDA by an alpha- bungarotoxinsensitive pathway. J Neurobiol 1998, 35:29-36.

8. Osborne-Hereford AV, Rogers SW, Gahring LC: Neuronal nicotinic alpha7 receptors modulate inflammatory cytokine production in the skin following ultraviolet radiation. J Neuroimmunol 2008, 193:130-139.

9. Mosely LH, Finseth F, Goody M: Nicotine and its effect on wound healing. Plast Reconstr Surg 1978, 61:570-575.

10. Zia S, Ndoye A, Lee TX, Webber RJ, Grando SA: Receptor-mediated inhibition of keratinocyte migration by nicotine involves modulations of calcium influx and intracellular concentration. J Pharmacol Exp Ther 2000, 293:973-981.

11. Chernyavsky Al, Arredondo J, Marubio LM, Grando SA: Differential regulation of keratinocyte chemokinesis and chemotaxis through distinct nicotinic receptor subtypes. J Cell Sci 2004, 117:5665-5679.

12. Arredondo J, Nguyen VT, Chernyavsky Al, Bercovich D, Orr-Urtreger A, Kummer W, Lips K, Vetter DE, Grando SA: Central role of alpha7 nicotinic receptor in differentiation of the stratified squamous epithelium. J Cell Biol 2002, 159:325-336.

13. Arredondo J, Nguyen VT, Chernyavsky Al, Bercovich D, Orr-Urtreger A, Vetter DE, Grando SA: Functional role of alpha7 nicotinic receptor in physiological control of cutaneous homeostasis. Life Sci 2003, 72:2063-2067.

14. Grando SA: Biological functions of keratinocyte cholinergic receptors. J Investig Dermatol Symp Proc 1997, 2:41-48.

15. Kurzen H, Berger H, Jager C, Hartschuh W, Naher H, Gratchev A, Goerdt S, Deichmann M: Phenotypical and molecular profiling of the extraneuronal cholinergic system of the skin. J Invest Dermatol 2004, 123:937-949.

16. Grando SA: Cholinergic control of epidermal cohesion. Exp Dermatol 2006, 15:265-282.

17. Homey B, Steinhoff M, Ruzicka T, Leung DY: Cytokines and chemokines orchestrate atopic skin inflammation. J Allergy Clin Immunol 2006, 118:178-189.

18. Nickoloff BJ, Xin H, Nestle FO, Qin JZ: The cytokine and chemokine network in psoriasis. Clin Dermatol 2007, 25:568-573.

19. Viola A, Luster AD: Chemokines and their receptors: drug targets in immunity and inflammation. Annu Rev Pharmacol Toxicol 2008, 48:171-197.

20. Rot $\mathrm{A}$, von Andrian $\cup \mathrm{H}$ : Chemokines in innate and adaptive host defense: basic chemokinese grammar for immune cells. Annu Rev Immunol 2004, 22:891-928.

21. Kelly $M$, Hwang JM, Kubes P: Modulating leukocyte recruitment in inflammation. J Allergy Clin Immunol 2007, 120:3-10.

22. Hume DA, Perry VH, Gordon S: The mononuclear phagocyte system of the mouse defined by immunohistochemical localization of antigen F4/80: macrophages associated with epithelia. Anat Rec 1984, 210:503-512.

23. Orr-Urtreger A, Kedmi M, Rosner S, Karmeli F, Rachmilewitz D: Increased severity of experimental colitis in alpha5 nicotinic acetylcholine receptor subunit-deficient mice. Neuroreport 2005, 16:1123-1127.

24. Salas R, Orr-Urtreger A, Broide RS, Beaudet A, Paylor R, De Biasi M: The nicotinic acetylcholine receptor subunit alpha 5 mediates short- term effects of nicotine in vivo. Mol Pharmacol 2003, 63:1059-1066.

25. Kedmi M, Beaudet AL, Orr-Urtreger A: Mice lacking neuronal nicotinic acetylcholine receptor beta4-subunit and mice lacking both alpha5and beta4-subunits are highly resistant to nicotine-induced seizures. Physiol Genomics 2004, 17:221-229.

26. Legler DF, Loetscher M, Roos RS, Clark-Lewis I, Baggiolini M, Moser B: B cell-attracting chemokine 1 , a human CXC chemokine expressed in lymphoid tissues, selectively attracts B lymphocytes via BLR1/CXCR5. J Exp Med 1998, 187:655-660.

27. Viola A, Molon B, Contento RL: Chemokines: coded messages for T-cell missions. Front Biosci 2008, 13:6341-6353.

28. Homey B, Alenius H, Muller A, Soto H, Bowman EP, Yuan W, McEvoy L, Lauerma Al, Assmann T, Bunemann E, Lehto M, Wolff H, Yen D,
Marxhausen H, To W, Sedgwick J, Ruzicka T, Lehmann P, Zlotnik A: CCL27CCR10 interactions regulate T cell-mediated skin inflammation. Nat Med 2002, 8:157-165.

29. Kunkel EJ, Butcher EC: Chemokines and the tissue-specific migration of lymphocytes. Immunity 2002, 16:1-4.

30. Fujimoto S, Uratsuji H, Saeki H, Kagami S, Tsunemi Y, Komine M, Tamaki K: CCR4 and CCR10 are expressed on epidermal keratinocytes and are involved in cutaneous immune reaction. Cytokine 2008, 44:172-178.

31. Scott DA, Martin M: Exploitation of the nicotinic anti-inflammatory pathway for the treatment of epithelial inflammatory diseases. World J Gastroenterol 2006, 12:7451-7459.

32. Klapproth $H$, Reinheimer T, Metzen J, Munch M, Bittinger F, Kirkpatrick CJ, Hohle KD, Schemann M, Racke K, Wessler I: Non-neuronal acetylcholine, a signalling molecule synthezised by surface cells of rat and man. Naunyn Schmiedebergs Arch Pharmacol 1997, 355:515-523.

33. Grando SA, Horton RM, Pereira EF, Diethelm-Okita BM, George PM, Albuquerque EX, Conti-Fine BM: A nicotinic acetylcholine receptor regulating cell adhesion and motility is expressed in human keratinocytes. J Invest Dermatol 1995, 105:774-781.

34. Wang $\mathrm{H}$, Yu M, Ochani M, Amella CA, Tanovic M, Susarla S, Li JH, Yang H, Ulloa L, Al-Abed Y, Czura CJ, Tracey KJ: Nicotinic acetylcholine receptor alpha7 subunit is an essential regulator of inflammation. Nature 2003, 421:384-388.

35. Matsunaga K, Klein TW, Friedman H, Yamamoto Y: Involvement of nicotinic acetylcholine receptors in suppression of antimicrobial activity and cytokine responses of alveolar macrophages to Legionella pneumophila infection by nicotine. J Immunol 2001, 167:6518-6524

36. Cloez-Tayarani I, Changeux JP: Nicotine and serotonin in immune regulation and inflammatory processes: a perspective. J Leukoc Biol 2007, 81:599-606.

37. Rosas-Ballina M, Tracey KJ: Cholinergic control of inflammation. J Intern Med 2009, 265:663-679.

38. Su X, Lee JW, Matthay ZA, Mednick G, Uchida T, Fang X, Gupta N, Matthay MA: Activation of the alpha7 $n A C h R$ reduces acid-induced acute lung injury in mice and rats. Am J Respir Cell Mol Biol 2007, 37:186-192.

39. Arredondo J, Hall LL, Ndoye A, Nguyen VT, Chernyavsky Al, Bercovich D, Orr-Urtreger A, Beaud AL, Grando SA: Central role of fibroblast alpha3 nicotinic acetylcholine receptor in mediating cutaneous effects of nicotine. Lab Invest 2003, 83:207-225.

40. Nguyen VT, Chernyavsky Al, Arredondo J, Bercovich D, Orr-Urtreger A Vetter DE, Wess J, Beaud AL, Kitajima Y, Grando SA, et al.: Synergistic control of keratinocyte adhesion through muscarinic and nicotinic acetylcholine receptor subtypes. Exp Cell Res 2004, 294:534-549.

41. Springer TA: Traffic signals on endothelium for lymphocyte recirculation and leukocyte emigration. Annu Rev Physiol 1995, 57:827-872.

42. Dustin ML, Carpen O, Springer TA: Regulation of locomotion and cell-cell contact area by the LFA-1 and ICAM- 1 adhesion receptors. J Immunol 1992, 148:2654-2663.

43. Campbell JJ, Butcher EC: Chemokines in tissue-specific and microenvironment-specific lymphocyte homing. Curr Opin Immunol 2000, 12:336-341.

44. Carlson NG, Wieggel WA, Chen J, Bacchi A, Rogers SW, Gahring LC Inflammatory cytokines IL-1alpha, IL-1 beta, IL-6, and TNF-alpha impart neuroprotection to an excitotoxin through distinct pathways. $J$ Immunol 1999, 163:3963-3968.

45. Giebelen IA, Le Moine A, van den Pangaart PS, Sadis C, Goldman M, Florquin S, van der Poll T: Deficiency of alpha7 cholinergic receptors facilitates bacterial clearance in Escherichia coli peritonitis. $J$ Infect Dis 2008, 198:750-757.

46. Davies P, Levy S, Pahari A, Martinez D: Acute nicotine poisoning associated with a traditional remedy for eczema. Arch Dis Child 2001, 85:500-502

47. Klaz I, Kochba I, Shohat T, Zarka S, Brenner S: Severe acne vulgaris and tobacco smoking in young men. J Invest Dermatol 2006, 126:1749-1752.

48. Naser SA, Ghobrial G, Miles $\mathrm{H}$ : Effect of nicotine on inflammatory bowel disease. Am J Gastroenterol 2001, 96:3455-3457.

49. Karban A, Eliakim R: Effect of smoking on inflammatory bowel disease: Is it disease or organ specific? World J Gastroenterol 2007, 13:2150-2152.

50. Galeazzi F, Blennerhassett PA, Qiu B, O'Byrne PM, Collins SM: Cigarette smoke aggravates experimental colitis in rats. Gastroenterology 1999, 117:877-883. 
51. Rubin DT, Hanauer SB: Smoking and inflammatory bowel disease. Eur J Gastroenterol Hepatol 2000, 12:855-862.

52. McGrath J, McDonald J, Macdonald J: Transdermal nicotine for induction of remission in ulcerative colitis. Cochrane Database Syst Rev 2004:CD004722.

53. Kalra R, Singh SP, Pena-Philippides JC, Langley RJ, Razani-Boroujerdi S, Sopori ML: Immunosuppressive and anti-inflammatory effects of nicotine administered by patch in an animal model. Clin Diagn Lab Immunol 2004, 11:563-568.

54. Misery L: Nicotine effects on skin: are they positive or negative? Exp Dermatol 2004, 13:665-670.

doi: 10.1186/1742-2094-7-38

Cite this article as: Gahring et al., Neuronal nicotinic alpha7 receptors modulate early neutrophil infiltration to sites of skin inflammation Journal of Neuroinflammation 2010, 7:38

Submit your next manuscript to BioMed Central and take full advantage of:

- Convenient online submission

- Thorough peer review

- No space constraints or color figure charges

- Immediate publication on acceptance

- Inclusion in PubMed, CAS, Scopus and Google Scholar

- Research which is freely available for redistribution

Submit your manuscript at www.biomedcentral.com/submit
C) Biomed Central 